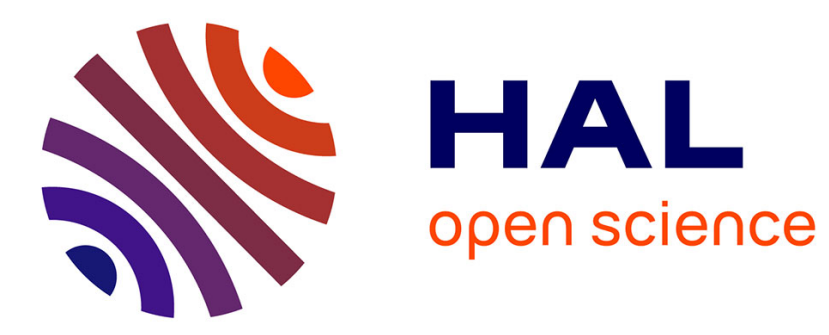

\title{
Temperature Dependent Local Instability of the Hg1212 Structure by Polarized EXAFS
}

\author{
N. Saini, M. Brunelli, A. Lanzara, M. Lusignoli, T. Rossetti, A. Bianconi, \\ Pierre Bordet, F. Duc, J. Hazemann, J. Karpinski
}

\section{> To cite this version:}

N. Saini, M. Brunelli, A. Lanzara, M. Lusignoli, T. Rossetti, et al.. Temperature Dependent Local Instability of the Hg1212 Structure by Polarized EXAFS. Journal de Physique IV Proceedings, 1997, 7 (C2), pp.C2-1245-C2-1246. 10.1051/jp4:19972215 . jpa-00255288

\section{HAL Id: jpa-00255288 https://hal.science/jpa-00255288}

Submitted on 1 Jan 1997

HAL is a multi-disciplinary open access archive for the deposit and dissemination of scientific research documents, whether they are published or not. The documents may come from teaching and research institutions in France or abroad, or from public or private research centers.
L'archive ouverte pluridisciplinaire HAL, est destinée au dépôt et à la diffusion de documents scientifiques de niveau recherche, publiés ou non, émanant des établissements d'enseignement et de recherche français ou étrangers, des laboratoires publics ou privés. 


\title{
Temperature Dependent Local Instability of the Hg1212 Structure by Polarized EXAFS
}

\author{
N.L. Saini, M. Brunelli, A. Lanzara, M. Lusignoli, T. Rossetti, A. Bianconi, P. Bordet*, F. Duc*, \\ J.L. Hazemann* and J. Karpinski** \\ Dipartimento di Fisica, Università di Roma "La Sapienza", P.A. Moro 2, 00185 Roma, Italy \\ * Laboratoire de Cristallographie CNRS, avenue des Martyrs, 38042 Grenoble, France \\ ** Solid State Physics Laboratory, Swiss Federal Institute of Technology, ETH Hönggeberg 8093 , \\ Switzerland
}

\begin{abstract}
The local structure of the $\mathrm{Hg}_{1} \mathrm{Ba}_{2} \mathrm{CaCu}_{2} \mathrm{O}_{6+\delta}(\mathrm{Hg} 1212)$ crystal has been investigated by temperature dependent polarized $\mathrm{Cu} \mathrm{K}$-edge extended x-ray absorption fine structure (EXAFS). We have observed an anomalous behavior of the local structure showing anomaly at around the superconducting transition temperature $T_{c}$ in the temperature dependence of the $\mathrm{Cu}-$ $O$ (planar) distance. The result suggests similarity of the temperature dependent local instability in the superconducting cuprates.
\end{abstract}

\section{NTRODUCTION}

One of the main debates in the high $\mathrm{T}_{\mathrm{C}}$ field is the instability of the local structure, diverging from the average one, due to the fact that the structural properties appear to be highly correlated with the (still unknown) electronic mechanism of superconductivity in these ceramics. This instability of the electronic properties in most of the cuprates has been seen by the experiments sensitive to the local structure showing temperature dependent anomalies around the superconducting critical temperature $T_{c}$ and above $T_{c}$ at a temperature $T^{*}[1]$.

$\mathrm{Cu}$ K-edge Extended X-ray Absorption Fine Structure (EXAFS) has proved its ability to probe the instable structure at the mesoscopic scale in various families of cuprate superconductors. Cu K-edge EXAFS studies with polarized $x$-rays and oriented single crystal samples have been used to characterize the lattice distortions by the direct measurement of distribution of the $\mathrm{Cu}-\mathrm{O}$ bond distances in these complex structures. Recently, exploiting the ability of the polarized EXAFS, we have determined the structure of the inhomogeneous $\mathrm{CuO}_{2}$ plane in the $\mathrm{La}_{2}-\mathrm{Sr}_{\mathrm{x}} \mathrm{CuO}_{4}$ (LSCO) [2-4] and $\mathrm{Bi}_{2} \mathrm{Sr}_{2} \mathrm{CaCu}_{2} \mathrm{O}_{8}$ (Bi2212) [5-6].

The $\mathrm{Hg}$-based high temperature superconductors have highest $\mathrm{T}_{\mathrm{c}}$ among the cuprate family and longest average $\mathrm{Cu}-\mathrm{O}$ distances indicating strong correlation between the superconductivity and the structural properties. To have further insight into the local structure of the potentially important $\mathrm{CuO}_{2}$ plane, we have made polarized $\mathrm{Cu} \mathrm{K}$-edge EXAFS measurements as a function of temperature on single crystal of $\mathrm{Hg}_{1} \mathrm{Ba}_{2} \mathrm{CaCu}_{2} \mathrm{O}_{6}+\delta$ ( $\left.\mathrm{Hg} 1212\right)$. The aim of this short report is to present the preliminary EXAFS results. We have been able to measure polarized EXAFS spectra on a very small crystal $(\sim 200 \mu \mathrm{m})$. The polarized EXAFS allowed us to separate the contribution of in plane backscatter from that of the out of plane. The temperature dependence of the in plane polarized $(\mathrm{E} / / \mathrm{ab})$ EXAFS is reported. The results suggest that the local structure of the $\mathrm{Hg} 1212$ system goes under anomalous structural changes at around $T_{C}$. The observation of the anomaly at $T_{c}$ suggests the general nature of the local structural distortions in the $\mathrm{CuO}_{2}$ plane of the high $\mathrm{T}_{\mathrm{c}}$ superconductors.

\section{EXPERIMENTAL}

The single crystal of $\mathrm{Hg} 1212$ was grown by high gas pressure technique [7]. The temperature dependent polarized Cu K-edge absorption measurements were performed on the beam-line CRG-IF, equipped with bent conically shaped Si(111) double crystal monochromator and sagittal focusing, at the European Synchrotron Radiation Facility (ESRF) at Grenoble. The crystal of size $200 \times 200 \mu \mathrm{m}^{2}$ showing $T_{c}=110 \mathrm{~K}$ (onset) was mounted in a closed-cycle He refrigerator and the temperature was monitored with an accuracy of $\pm 1 \mathrm{~K}$. The spectra were recorded in the fluorescence yield mode using a 5 -element Ge detector system. The spectra were repeated for the reproducibility. The EXAFS signal $\chi=\left(\alpha-\alpha_{0}\right) / \alpha_{0}$, where $\alpha$ is the absorption coefficient and $\alpha_{0}$ is the so called atomic absorption, was extracted from the absorption spectrum using standard procedure [8] and corrected for fluorescence self absorption [9].

\section{RESULTS AND DISCUSSION}

The Fourier transform (FT) of the extracted EXAFS signal (multiplied by $\mathbf{k}^{2}$ ) from the E/ ab polarized Cu K-edge absorption of the $\mathrm{Hg} 1212$ single crystal, at a representative temperature $(130 \mathrm{~K})$ is shown in Fig. 1. The Fourier transform has been performed in the $\mathrm{k}$ range between $\mathrm{k}_{\min }=3 \AA^{-1}$ to $\mathrm{k}_{\max }=16 \AA^{-1}$ using a Gaussian window. The main peaks in the Fourier 
transform (FT) reflect the distribution of atoms in the E//ab direction. The position corresponding to the FT peaks in Fig. 1 do not give measure of the real inter atomic distances as the FT is not corrected for the phase shifts. The strong contribution from the $\mathrm{Cu}-\mathrm{O}$ (planar) pair (at $1.9 \AA$ distance) is reflected by a FT peak at $\sim 1.6 \AA$ effective distance.

The Cu-O(planar) EXAFS of the first shell was isolated by Fourier filtering and corrected by theoretically calculated phase shifts. The EXAFS was modelled using curved wave theory. The number of parameters determined by the EXAFS analysis is limited by $N=(2 \Delta R \Delta k) / \pi$. In the present case, the $\Delta R=0.8 \AA, \Delta k=10 \AA^{-1}\left(3-13 \AA^{-1}\right)$ and hence the number of parameters to be fitted is limited by about 5 . In the analysis all the parameters including the effective coordination number (which agrees well with the parameters reported earlier $[2,4-5,10]$ for $\mathrm{Cu}-\mathrm{O}$ pairs in different systems) were fixed while the radial distance $(R)$ and the Debye Waller factor $\left(\sigma^{2}\right)$ for the $\mathrm{Cu}-\mathrm{O}$ (planar) pair were allowed to vary. Thus the present analysis is essentially a two parameter fit.

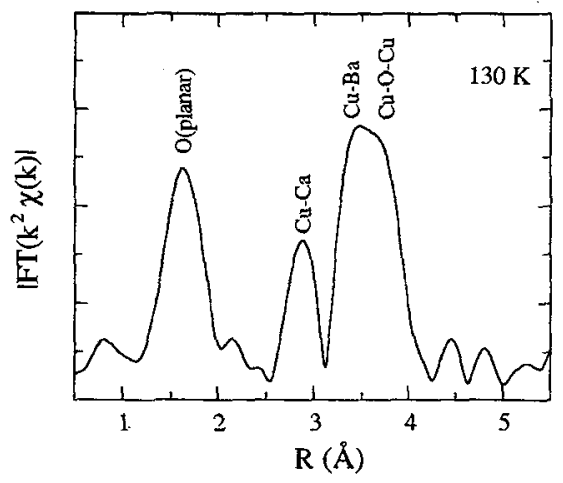

Figure 1: Fourier transform of the experimental E//ab distance EXAFS spectrum at $130 \mathrm{~K}$

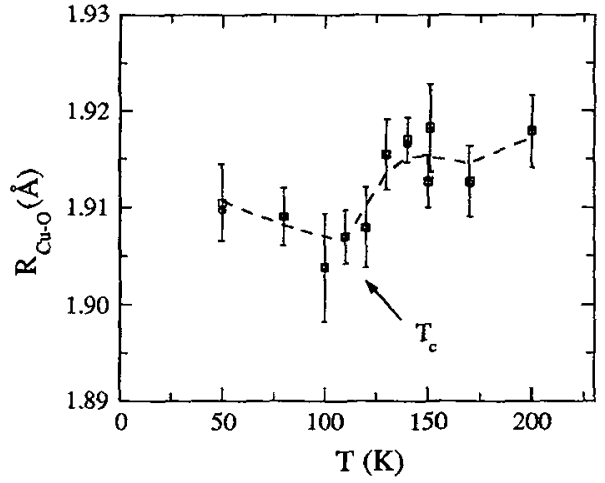

Figure 2: Temperature dependence of the $\mathrm{Cu}-\mathrm{O}$ (planar) measured by EXAFS.

The temperature dependence of the $\mathrm{Cu}-\mathrm{O}$ (planar) distance is shown in the Fig. 2. The $\mathrm{Cu}-\mathrm{O}$ (planar) distance is temperature dependent and there appears to be anomalous change at $T_{\mathrm{c}}$. This anomalous behavior is similar to one observed in the other cuprate superconductors [3-6]. The result suggests that inhomogeneity of the $\mathrm{CuO}_{2}$ plane, responsible for the anomalous behaviour, is a common feature for high $\mathrm{T}_{\mathrm{C}}$ superconductivity.

The similarity in the structural anomalies at around the superconducting transition temperature $\mathrm{T}_{\mathrm{c}}$ merely highlights the importance of the correlation between the charge and the lattice distortions for the superconductivity in the high $T_{c}$ cuprate superconductors. The local lattice instability at low temperature has been associated with charge localization in a distorted local lattice i.e., polarons that coexist with itinerant charge carriers in the metallic undistorted $\mathrm{CuO}_{2}$ plane [11].

\section{Acknowledgements}

We would like to thank the Istituto Nazionale di Fisica della Materia (INFM), Istituto Nazionale di Fisica Nucleare (INFN) and Consiglio Nazionale delle Ricerche (CNR) for financial assistance.

\section{References}

[1] Egami T. and Billinge S.J. L. ,Progress in Material Science 38 (1994) 359; and references therein.

[2] Bianconi A, Saini N.L., Lanzara A., Missori M., Rossetti T., Oyanagi H., Yamaguchi H., Oka K. and Ito T., Phys. Rev. Lett. 76 (1996) 3412.

[3] Saini N.L., Lanzara A., Missori M., Rossetti T., Bianconi A., Oyanagi H., Yanaguchi H., Oka K. and Ito T., Physica C 251, (1995) 383.

[4] Saini N.L., Lanzara A., Bianconi A., Oyanagi H., Yamaguchi H., Oka K. and Ito T., Physica C (in press, 1996).

[5] Bianconi A., Saini N.L., Rossetti T., Lanzara A., Perali A., Missori M., Oyanagi H., Yamaguchi H., Nishihara Y. and Ha D. H., Phys. Rev. B (to be published, 1996).

[6] Bianconi A. and Missori M., Oyanagi H., Yamaguchi H., Ha D. H., Nishihara Y. and Della Longa S. Europhys. Lett. 31 (1995) 411.

[7] Karpinski J., Schwer H., Mangelschots I. , Conder K., Morawski A. , Lada T. , Paszewin A., Physics C 234 (1994) 10.

[8] X-Ray Absorption: Principle, Applications Techniques of EXAFS, SEXAFS and XANES, R. Prinz and D. Koningsberger Eds. (J. Wiley and Sons, New York 1988).

[9] Tröger L., Arvanitis D., Baberschke K., Michaelis H., Grimm U. and Zschech E., Phys. Rev. B 46 (1992) 3283; Goulon J., GoulonGinet C., Cortes R. and Dubois J.M., J. Phys. I (France) 43 (1982) 539.

[10] Li G.G., Bridges F. and Booth C.H., Phys. Rev. B 52, (1995) 6332.

[11] Bianconi A. Solid State Commun. 91, (1994) 1; Bianconi A. and Missori M., Solid State Commun. 91 (1994) 287. 